\title{
Improving performance with sophisticated master production scheduling
}

\author{
Patrik Jonsson \& Linea Kjellsdotter Ivert \\ Department of Technology Management and Economics \\ Chalmers University of Technology \\ Sweden \\ E-mail: Patrik.jonsson@chalmers.se
}

\begin{abstract}
Literature addressing master production scheduling (MPS) typically focuses on the development of sophisticated MPS methods with the expectation that these methods will result in feasible plans and improved performance. However, empirical evidence showing that sophisticated methods are better than simpler ones remains scarce, and companies have reported difficulties with using sophisticated planning methods. In this study, we therefore investigate how sophisticated MPS methods impact three perception-based performance variables - namely, plan feasibility, inventory turnover rate, and delivery service-while accounting for the complexities of planning environments and MPS maturity. We define six MPS methods, ranging from those that ignore capacity to those exhibiting capacity-constrained planning using optimisation. An analysis of survey data from a sample of Swedish manufacturing companies reveals a significant negative effect of less sophisticated methods compared to highly sophisticated ones in terms of plan feasibility, as well as a significant negative effect of the simplest method in considering available capacity compared to highly sophisticated methods in terms of delivery service. The maturity of the MPS process most significantly impacts all performance measures, whereas planning environment complexity shows only a weak negative impact. Findings also indicate that both MPS process maturity and sophisticated MPS methods mediate the negative performance prompted by complex planning environments. Results thus suggest that sophisticated MPS may generally affect performance both directly and indirectly. Using sophisticated MPS methods reduces the negative effects of complex planning environments and results in more feasible plans irrespective of environment complexity and process maturity.
\end{abstract}

Keywords: Master production scheduling (MPS), sophisticated MPS methods, MPS maturity, planning environment complexity, performance

\section{Introduction}

Master production scheduling (MPS) is the process of developing plans for identifying which quantities of products should be manufactured during certain periods. MPS therefore drives operations in terms of what is assembled, manufactured, and bought (Vieira and Favaretto, 2006). MPS additionally provides information for sales regarding what can be promised to customers and when deliveries can be made, which makes the method a vital link between customer order management and production 
Full reference to this article: Jonsson, P. and Kjellsdotter Ivert, L. (2015). "Improving performance with sophisticated master production scheduling". International Journal of Production Economics, Vol. 168, pp. 118-130. D0I:10.1016/j.ijpe.2015.06.012

(Zhao et al., 2001). These characteristics mean that MPS is the basis for meeting delivery promises without inducing high inventory levels, as well as for resolving tradeoffs between sales and manufacturing (Jacobs et al., 2011).

Despite the importance of MPS, literature focusing on ways to improve production planning and scheduling processes remains limited (de Snoo et al., 2011). Most literature concerning MPS addresses the development of sophisticated methods with the assumption that these methods result in feasible plans and improved performance in plants (e.g., Bakhrankova, 2010; Chen and Ji, 2006; Chu, 1995; Robinson et al., 2008; Vieira and Favaretto, 2006; Zhao et al., 2001). Today, standardised commercial off-theshelf software, including enterprise resource planning (ERP) and advanced planning and scheduling (APS) systems, has improved the accessibility of using sophisticated methods such as constraint-based planning supported by heuristics and/or optimisation (Entrup, 2005; Hvolby and Steger-Jensen, 2010; Kreipl and Dickersbach, 2007; Stadtler and Kilger, 2010).

Nevertheless, not everyone is convinced that sophisticated methods can precipitate outstanding planning and scheduling (Carvalho et al., 2014; de Kok and Graves, 2003; Jackson et al., 2004; Jonsson and Mattsson, 2009). Studies indicate several problems involved in successfully using sophisticated methods in planning processes, including difficulties with understanding output, personnel's lack of motivation to update data, and small changes on the shop floor that result in major changes in the schedule (Carvalho et al., 2014; Ivert and Jonsson, 2011; Jonsson, 2008; Kreipl and Dickersbach, 2007). As many companies are prepared to invest or have already invested in standardised commercial off-the-shelf software, it is of necessity to evaluate how using sophisticated methods can affect performance.

To understand how sophisticated MPS methods impact planning performance, it is important to accommodate contextual and organisational aspects often indicated in explanations of why some companies succeed in production planning and scheduling while others do not (e.g., Jackson et al., 2004; Jonsson and Mattsson, 2008; Setia et al., 2008). Literature on the topic stresses the difficulty of conducting MPS in complex environments (Soares and Vieira, 2009; Tenhiälä, 2011) and that companies with mature processes achieve better performance than those with less mature processes (Heinrich and Simchi-Levi, 2005). In this study, we seek to understand the impact of sophisticated MPS methods by considering the effects of planning environment complexity and MPS maturity. To our knowledge, no study has yet investigated how sophisticated planning methods affect performance in light of contextual and organisational aspects. Furthermore, only few studies have investigated the effects of MPS methods in practice. Understanding the importance of planning environment complexity, MPS maturity, and sophisticated MPS methods is essential for achieving state-of-the-art MPS. Is it that high complexity in the environment makes MPS so difficult to carry out that using MPS methods and appealing to levels of MPS maturity do not matter? Or is the importance of context exaggerated insofar that we hide behind the idea that planning environments are so unique that applying available methods and practices is impossible? How important is it to implement a mature process and use sophisticated methods? Should we invest in planning software employing sophisticated methods, or is it better to invest in the process? The purpose of the study described in this paper was to investigate the impact of sophisticated MPS methods in light of planning environment complexity and MPS maturity on plan feasibility, inventory turnover rate, and delivery service. In the following sections, MPS and MPS 
Full reference to this article: Jonsson, P. and Kjellsdotter Ivert, L. (2015). "Improving performance with sophisticated master production scheduling". International Journal of Production Economics, Vol. 168, pp. 118-130. D0I:10.1016/j.ijpe.2015.06.012

performance are defined, hypotheses are formulated, and an analysis of survey data purporting a sample of Swedish manufacturing companies is reported.

\section{Conceptual Model and Hypotheses}

\subsection{MPS and MPS performance}

MPS can be defined as a process that involves developing and establishing plans for a company's sales and production operations. It is typically conducted weekly at the product level, spans a timeframe of a couple of months up to a year, and consists of five activities (Jacobs et al., 2011; Jonsson and Mattsson, 2009): forecasting future demand, generating a preliminary market delivery plan, generating a preliminary production plan, adapting plans as necessary by reconciling drafted plans and the conditions for realising them, and settling on prepared plans. In broad terms, it is possible to distinguish two planning approaches for MPS: iterative, rough-cut capacity planning (RCCP) or concurrent advanced planning and scheduling (APS) (APICS, 2012). In RCCP, the five activities occur sequentially, one after the other. Critical resources are identified based on the needs derived from the delivery plan, after which required and available capacities are calculated from the preliminary production plan. Once critical resources are identified, required capacity is balanced with the planned available capacity. In APS, by contrast, steps 3-5 occur simultaneously; an optimisation approach is applied in which a production plan is generated by immediately considering critical resources.

In the process of MPS, particularly when accessing performance, it is important to differentiate the output from the effect of MPS. The output of MPS refers to the production plan indicating what to build and when (i.e., plan feasibility), whereas the effect of MPS, if beneficial, refers to the improved performance of the plant and, in turn, the positive impact on profit and competitiveness (i.e., plant performance).

Although this logic holds that MPS methods affect plan feasibility, which influences plant performance-for example, 'Poor methods yield plans that are either too loose and result in excessive lead times or too tight and result in failures to keep promised delivery dates' (Tenhiälä, 2011)—plan feasibility and plant performance are not automatically related. One does not by definition achieve great effects only because the output is superior. Banker et al. (2006) recognise the risk of examining only direct relationships between information technology (IT) resources and a firm's overall performance, which can promote misguided conclusions since advantages associated with IT-enabling business processes may be appropriated before they are reflected at the plant level. Ivert and Jonsson (2010) highlight the many factors that influence plant performance and thereby suggest the importance of accessing the performance of sophisticated methods at the level closest to their use.

\subsection{Sophisticated MPS methods}

In terms of sophisticated MPS, it is possible to define six methods, ranging from those that do not consider capacity to those that exhibit capacity-constrained planning using optimisation. In Method 1, which corresponds to Tenhiälä’s (2011) 'nonsystematic methods', the final production plan is unconstrained and based directly on the delivery plan. By contrast, Methods 2 to 5 stipulate iterative steps, all in accordance with RCCP, that are used in the development of a feasible production plan. Methods 2 and 3 are similar to Tenhiälä's (2011) RCCP method, though Method 3 is more 
Full reference to this article: Jonsson, P. and Kjellsdotter Ivert, L. (2015). "Improving performance with sophisticated master production scheduling". International Journal of Production Economics, Vol. 168, pp. 118-130. DOI:10.1016/j.ijpe.2015.06.012

sophisticated than Method 2 insofar that the former balances capacity according to certain goals for the inventory or order backlog level. Method 4 corresponds to capacity requirement planning (Jacobs et al., 2011), while Method 5 corresponds to Tenhiälä's (2011) 'capacity levelling', in which rescheduling occurs automatically in cases of capacity overload or underload. Lastly, in Method 6, which corresponds to Tenhiälä's (2011) optimisation, the development of production plans occurs more or less automatically. Methods 1-3 can be applied with simple planning software support, if any at all, while Methods 4-6 require planning software (e.g., ERP and APS systems) to identify capacity imbalances and understand their consequences. Table 1 describes each of the six methods according to its respective goal, scope, procedure, automation, and IT support.

Table 1 Sophisticated master production scheduling (MPS) methods

\begin{tabular}{|c|c|c|c|c|c|}
\hline \multirow{2}{*}{$\begin{array}{l}\text { Sophisticated } \\
\text { MPS method }\end{array}$} & \multicolumn{5}{|c|}{ Method characteristics } \\
\hline & Goal & Scope & Procedure & Automation & IT support \\
\hline $\begin{array}{l}\text { 1. No } \\
\text { consideration of } \\
\text { capacity }\end{array}$ & $\begin{array}{l}\text { Production } \\
\text { plan }\end{array}$ & $\begin{array}{l}\text { No capacity } \\
\text { planning }\end{array}$ & None & None & None \\
\hline $\begin{array}{l}\text { 2. Estimated } \\
\text { balancing }\end{array}$ & $\begin{array}{l}\text { Feasible } \\
\text { production } \\
\text { plan }\end{array}$ & $\begin{array}{l}\text { Focus on } \\
\text { capacity } \\
\text { planning }\end{array}$ & $\begin{array}{l}\text { RCCP: No } \\
\text { consideration of } \\
\text { certain goals }\end{array}$ & Manually & $\begin{array}{l}\text { MS Excel or } \\
\text { similar }\end{array}$ \\
\hline $\begin{array}{l}\text { 3. Estimated } \\
\text { balancing with } \\
\text { goal }\end{array}$ & $\begin{array}{l}\text { Feasible } \\
\text { production } \\
\text { plan }\end{array}$ & $\begin{array}{l}\text { Focus on } \\
\text { capacity } \\
\text { planning }\end{array}$ & $\begin{array}{l}\text { RCCP: } \\
\text { Consideration of } \\
\text { goals for } \\
\text { inventory or } \\
\text { order stock } \\
\text { levels }\end{array}$ & Manually & $\begin{array}{l}\text { MS Excel or } \\
\text { similar }\end{array}$ \\
\hline $\begin{array}{l}\text { 4. Balancing } \\
\text { with system } \\
\text { support }\end{array}$ & $\begin{array}{l}\text { Feasible } \\
\text { production } \\
\text { plan }\end{array}$ & $\begin{array}{l}\text { Focus on } \\
\text { capacity } \\
\text { planning }\end{array}$ & $\begin{array}{l}\text { RCCP: } \\
\text { Consideration of } \\
\text { goals for } \\
\text { inventory or } \\
\text { order stock } \\
\text { levels }\end{array}$ & $\begin{array}{l}\text { Automatic } \\
\text { suggestion of } \\
\text { rescheduling }\end{array}$ & $\begin{array}{l}\text { ERP/APS } \\
\text { system }\end{array}$ \\
\hline $\begin{array}{l}\text { 5. Capacity } \\
\text { levelling }\end{array}$ & $\begin{array}{l}\text { Near-optimal } \\
\text { production } \\
\text { plan }\end{array}$ & $\begin{array}{l}\text { Focus on } \\
\text { capacity } \\
\text { planning }\end{array}$ & $\begin{array}{l}\text { RCCP/APS: } \\
\text { Consideration of } \\
\text { goals for } \\
\text { inventory or } \\
\text { order stock } \\
\text { levels }\end{array}$ & $\begin{array}{l}\text { Automatic } \\
\text { rescheduling } \\
\text { with help of } \\
\text { mathematical } \\
\text { heuristics }\end{array}$ & APS system \\
\hline $\begin{array}{l}\text { 6. Optimal } \\
\text { balancing }\end{array}$ & $\begin{array}{l}\text { Optimal } \\
\text { production } \\
\text { plan }\end{array}$ & $\begin{array}{l}\text { Focus on } \\
\text { supply chain } \\
\text { (i.e., } \\
\text { purchasing, } \\
\text { production, } \\
\text { logistics, and } \\
\text { finances) }\end{array}$ & $\begin{array}{l}\text { APS: Create the } \\
\text { MPS while } \\
\text { considering } \\
\text { capacity and } \\
\text { certain business } \\
\text { goals }\end{array}$ & $\begin{array}{l}\text { Automatic } \\
\text { generation of } \\
\text { production } \\
\text { plans with the } \\
\text { help of } \\
\text { optimisation } \\
\text { algorithms }\end{array}$ & APS system \\
\hline
\end{tabular}

Many studies have emphasised the necessity of sophisticated methods for creating production plans (Ivert and Jonsson, 2010; Stadtler and Kilger, 2010; Vieira and Favaretto, 2006). It is often considered to be impossible to develop feasible production plans without taking capacity limitations and various business objectives into consideration (Fleischmann and Meyr, 2003; Vieira and Favaretto, 2006). Over the years, researchers and software vendors have put forth great effort in developing mathematical algorithms that enable the capacity levelling of production plans (Lin et 
Full reference to this article: Jonsson, P. and Kjellsdotter Ivert, L. (2015). "Improving performance with sophisticated master production scheduling". International Journal of Production Economics, Vol. 168, pp. 118-130. D0I:10.1016/j.ijpe.2015.06.012

al., 2007; Tenhiälä, 2011). At the same time, individual studies have found that using constraint-based planning and/or optimisation in developing production plans allows positive outputs, including synchronised plans, reduced inventory levels, increased customer service, and improved capacity use (Reuter, 2005; Rudberg and Thulin, 2009; Wagner and Meyer, 2005). By extension, other research indicates that using sophisticated methods can improve the use of production plans given that investment in a sophisticated method per se increases interest in the process and its outputs among personnel (Ivert and Jonsson, 2014).

\subsection{Planning environment complexity}

It has been argued that planning becomes more difficult to conduct as environments become more complex (Günter, 2005) and that this condition-namely, planning environment complexity-negatively impacts production plans and plant performance (Bozarth et al., 2009; de Snoo et al., 2011). According to Vieira and Favaretto (2006), as environments become more complex in terms of the number of products, resources, raw materials, set-up times, restrictions in capacity, uncertainties in demand, supply and production, the more difficult it becomes to conduct MPS and generate feasible production plans. An increased number of entities (e.g., products, resources, and raw materials) increases the number of planning activities (Bozarth et al., 2009; Jacobs et al., 2011), whereas a high level of variability in production, demand, and supply makes it difficult to establish and adhere to an effective production plan (Wiers, 2009). The planning environment variables identified by Vieira and Favaretto (2006) correspond well with the dimensions constituting supply chain complexity as defined by Bozarth et al. (2009). Accordingly, planning environment complexity is conceived as the level of detail and dynamic complexity that affects MPS; detail complexity refers to the distinct number of components and parts that affects the MPS; and dynamic complexity means the unpredictability of the input of the system and of the system's response to that input (i.e., uncertainties in demand, production, and supply) (Mula et al., 2006). Bozarth et al. (2009) have found that supply chain characteristics that address constraint and uncertainties affect the performance of the production schedule and the plant more than characteristics that address the number of entities.

\subsection{MPS maturity}

As firms increasingly view their organisations from process-based perspectives, the concept of process maturity becomes increasingly important (Lockamy et al., 2008). Process maturity proposes that a process has a life cycle that can be assessed according to how well the process is explicitly defined, managed, measured, and controlled (Lockamy et al., 2008). As processes mature, process capability improves, which in turn improves the performance of the organisation (e.g., Heinrich and Simchi-Levi, 2005; Lockamy and McCormack, 2004). Using maturity as a measure for evaluating an organisation's capabilities in certain areas has become quite popular (de Bruin and Rosemann, 2005), and several models for measuring process maturity have been proposed (e.g., de Bruin and Rosemann, 2005; Fisher, 2004; Grimson and Pyke, 2007; Heinrich and Simchi-Levi, 2005; Lockamy and McCormack, 2004; Thomé et al., 2011). Most process maturity models in current literature relate to the process of software development and project management (Lockamy et al., 2008); however, recent studies in production planning and control have begun to address aspects linked to maturity (de 
Full reference to this article: Jonsson, P. and Kjellsdotter Ivert, L. (2015). "Improving performance with sophisticated master production scheduling". International Journal of Production Economics, Vol. 168, pp. 118-130. D0I:10.1016/j.ijpe.2015.06.012

Snoo et al., 2011; Grimson and Pyke, 2007; Ivert and Jonsson, 2010; Thomé et al., 2011).

Grimson and Pyke (2007), Oliva and Watson (2011), and Tuomikangas and Kaipia (2014) have all emphasised the importance of collaboration and meetings in production planning processes, in addition to stressing that planning meetings to address the development of preliminary and final production plans increases the possibility of achieving positive results. Studies have furthermore shown that organisational infrastructure is of particular importance in establishing high performance rates (de Snoo et al., 2011; Zhou et al., 2009). An advantage of involving people from different functions in the planning process is increased commitment to the plans themselves (Jonsson et al., 2007). Berglund and Karltun (2007) and Carvalho et al. (2014) have highlighted that the degree of proximity among employees is a factor that influences performance. MPS may be performed as an automatic calculative procedure involving one person, yet can also be managed by a responsible planning organisation that involves key personnel from different departments, each performing a distinct planning activity that serves as an input to the subsequent activity (Ivert and Jonsson, 2010).

\subsection{Research model}

Figure 1 illustrates the research model used in the present study. Based on the literature review, three hypotheses are generated. Given the study's chief aim to explain how sophisticated MPS methods affect performance, we consider the effects of planning environment complexity and MPS maturity upon performance first and second in the research model. Thereafter, the additional contribution of sophisticated MPS methods to performance is examined. From this, the hypotheses are as follows:

H1: Greater planning environment complexity negatively impacts MPS performance.

H2: Greater MPS maturity positively impacts MPS performance, after the effect of planning environment complexity is controlled for.

H3: More sophisticated MPS methods more positively impact MPS performance than less sophisticated methods, after the effects of planning environment complexity and MPS maturity are controlled for.

Aside from planning environment complexity, MPS maturity, and the sophistication of MPS methods, other variables can also affect MPS performance. Firm size and flexibility in increasing and decreasing capacity are used here as control variables. Company size is often emphasised in the literature as a variable that might influence the performance of planning approaches and methods (e.g., Jonsson, 2008; Schroeder et al., 1981). Larger companies often have more complex material flows and more products, resources, and cross-functional relationships, which might result in a more complex planning process. The company's flexibility with adjusting capacity should also influence performance measures. When the limited available capacity is not taken into consideration, the possibility of adjusting the available capacity to make use of the production plan becomes important. The more sophisticated the MPS method for the development of the production plan, the less important it is to have high-capacity flexibility, since capacity is taken into consideration in an increasingly sophisticated manner. 
Full reference to this article: Jonsson, P. and Kjellsdotter Ivert, L. (2015). "Improving performance with sophisticated master production scheduling". International Journal of Production Economics, Vol. 168, pp. 118-130. DOI:10.1016/j.ijpe.2015.06.012

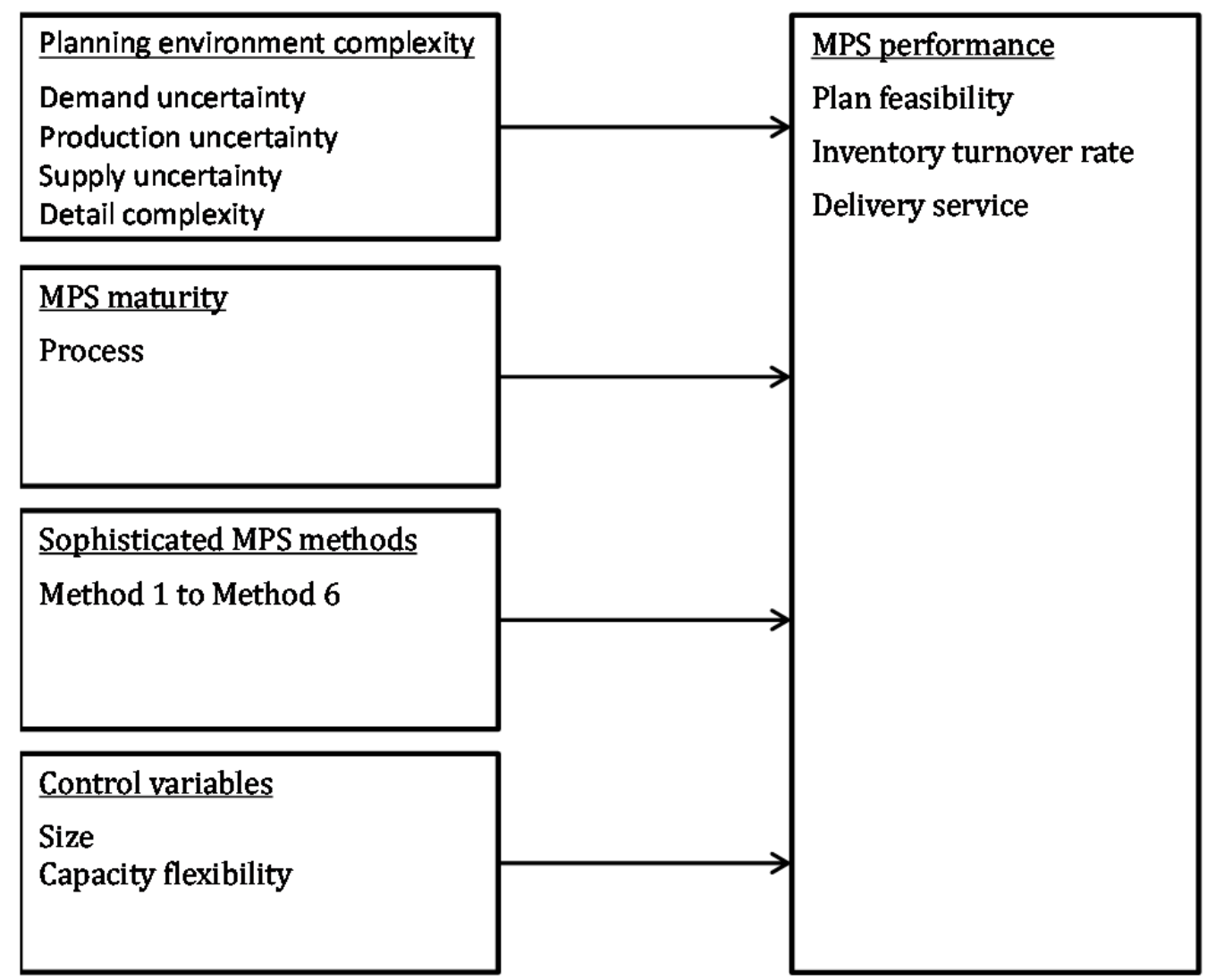

Fig. 1. Research model.

\section{Method}

\subsection{Sample selection and data collection}

The study population consists of Swedish manufacturing companies with more than 100 employees. Since Sweden represents a wide range of manufacturing industries (Table 2) and has been deemed an early adopter of new IT (Olhager and Selldin, 2003), the use of sophisticated MPS methods is not uncommon in the country. Addresses of manufacturing companies were taken from the Swedish postal service's database, resulting in 1,103 unique firms, each of which was sent a questionnaire. In all, 326 completed questionnaires were returned, for a response rate of about $30 \%$. 
Full reference to this article: Jonsson, P. and Kjellsdotter Ivert, L. (2015). "Improving performance with sophisticated master production scheduling". International Journal of Production Economics, Vol. 168, pp. 118-130. DOI:10.1016/j.ijpe.2015.06.012

Table 2 Distribution of manufacturing industries in the study population

\begin{tabular}{|l|l|l|}
\hline Industry & Selection (population) & Responses \\
\hline 1. Food and beverage & 118 & 30 \\
\hline 2. Textiles & 14 & 5 \\
\hline 3. Wood & 95 & 24 \\
\hline 4. Pulp and paper & 62 & 17 \\
\hline 5. Chemistry & 60 & 30 \\
\hline 6. Pharmaceuticals & 18 & 1 \\
\hline 7. Rubber and plastic & 84 & 21 \\
\hline 8. Steel and metal works & 69 & 19 \\
\hline 9. Metal goods & 174 & 59 \\
\hline 10. Electronics & 51 & 16 \\
\hline 11. Electrical components & 104 & 33 \\
\hline 12. Machinery & 50 & 15 \\
\hline 13. Vehicles & 50 & 16 \\
\hline 14. Transport & 44 & 12 \\
\hline 15. Furniture & 34 & 9 \\
\hline 16. Other & 25 & 8 \\
\hline & Total: 1,052 & Total: 315 \\
\hline
\end{tabular}

Note: The selection included 1,103 firms, and the number of responses was 326, yet our database contained industry and firm size information for only 1,052 of the 1,103 addresses. As such, 315 of the 326 responses came from these 1,052 companies.

\subsection{Key informant and nonresponse bias}

Ideally, questionnaire respondents were production managers. If the company had no production manager available to respond, then either a planning manager or, if none were available, a supply chain and logistics manager completed the questionnaire. All respondents were expected to be professionally involved in the MPS process and to hold one of the above positions, all of which relate to production planning and control.

While completing the questionnaire, respondents were asked to focus on the MPS process, which was defined as 'the process of preparing and establishing the quantities that should be manufactured per a set period for a production site'. Respondents were asked whether they considered themselves to have sufficient knowledge of the MPS process in order to answer the survey questions. A seven-point scale with potential answers ranging from 'strongly disagree' to 'strongly agree' was explained. Responses of the 48 respondents who did not answer this question and the 16 respondents who selected 1, 2, or 3 were excluded from the data, since their answers could not verify that they had enough knowledge of the MPS processes in their firms to answer the questionnaire accurately. The mean value of the answers of the remaining 262 respondents to this question was 6.00 , which suggests that key informant bias does not significantly affect the data.

Nonresponse bias tests were conducted by comparing firm size and industry within the manufacturing sector between early and late responses and between all respondents and the entire sample. The independent variable means were also compared between early and late responses. Chi-square tests showed no significant $(p<.05)$ differences among the four industry groups composed of the 16 industries shown in Table 1 (Group 1 = Industry 1, Group 2 = Industries 2-7, Group 3 = Industries 8-14, and Group $4=$ Industries 15-16). There were, however, significantly (Mann-Whitney test, $p<.05$ ) fewer small firms in the group of late responses than in the group of early responses, as well as among all respondents compared to the sample when three sizes $(<100$ employees, 100 to 300 employees, and $>300$ employees) were compared. Both tests 
Full reference to this article: Jonsson, P. and Kjellsdotter Ivert, L. (2015). "Improving performance with sophisticated master production scheduling". International Journal of Production Economics, Vol. 168, pp. 118-130. DOI:10.1016/j.ijpe.2015.06.012

consequently indicated that respondents represented a group slightly biased toward larger firms, most likely because we focused on large firms when making reminder phone calls, for we especially sought users of sophisticated MPS methods and expected large firms to more often be such users than small firms. This slight bias toward larger firms was not considered to pose a major problem for the study, since the survey approach is explanatory and we needed enough respondents representing both simple and sophisticated MPS methods. No mean value of the independent variables (i.e., capacity flexibility, demand uncertainty, production uncertainty, supply uncertainty, detail complexity, process maturity, organisation, and sophistication of the MPS method) differed significantly ( $t$ tests, $p<.05$ ) between early and late responses.

Table 2 shows that the sample represents a wide spread of manufacturing industries, while Table 3 shows more demographic characteristics of the respondents. Most customers were manufacturing companies, and those with fewer than 100 employees were excluded from the population. Though $36 \%$ of respondents indicated that their firms retained fewer than 100 employees, only 8\% reported having a turnover of less than $€ 12$ million. We therefore acknowledge that we did not include many very small companies in the sample.

Respondents represented different manufacturing processes (Hill, 1993) to form an even mix of human- and machine-intensive production. If their companies had two tactical planning levels (e.g., sales and operations planning [S\&OP] and MPS), then respondents were asked to focus on the level in which end products were more clearly the planning objects. Most respondents focused on a weekly process with a 6-month planning horizon, which corresponds well with a so-called 'traditional' MPS process (e.g., Jacobs et al., 2011). Several companies continued to use monthly or even quarterly processes with longer planning horizons, which indicates that they likely have adopted a 'common' process at the S\&OP and MPS levels. Customers, product type, manufacturing process, and human-intensive production variables were listed on a nominal scale. Size, frequency, and horizon variables were listed on an ordinal scale. 
Full reference to this article: Jonsson, P. and Kjellsdotter Ivert, L. (2015). "Improving performance with sophisticated master production scheduling". International Journal of Production Economics, Vol. 168, pp. 118-130. DOI:10.1016/j.ijpe.2015.06.012

Table 3 Demographics of the sample distribution

\begin{tabular}{|l|l|}
\hline Demographic variables and alternatives & Number of responses (\% of all responses) \\
\hline Customers: & \\
Wholesalers & $36(14 \%)$ \\
Retailers & $26(10 \%)$ \\
Manufacturers & $117(67 \%)$ \\
End consumers & $20(8 \%)$ \\
\hline Product type: & \\
Raw material and components & $74(29 \%)$ \\
End products & $185(71 \%)$ \\
\hline Size (turnover): & \\
$<€ 12 \mathrm{M}$, & $22(8 \%)$ \\
$€ 12-60$ M & $128(50 \%)$ \\
$>€ 60$ M & $107(42 \%)$ \\
\hline Size (employees): & \\
94 (36\%) <100 & $94(36 \%)<100$ \\
$104(40 \%)$ 100-300 & $104(40 \%) 100-300$ \\
49 (19\%) 301-1,000 & $49(19 \%) 301-1,000$ \\
15 (6\%) >1,000 & $15(6 \%)>1,000$ \\
\hline Manufacturing process: & \\
Continuous process & $81(31 \%)$ \\
Continuous line & $41(16 \%)$ \\
Frequent batch manufacturing & $89(34 \%)$ \\
Infrequent batch manufacturing (less than monthly) & $16(6 \%)$ \\
Jobbing (one-off manufacturing) & $34(13 \%)$ \\
\hline Human intensive production: & \\
131 (51\%) human-intensive production & $131(51 \%)$ \\
127 (49\%) machine-intensive production & $127(49 \%)$ \\
\hline MPS planning frequency: & \\
152 (59\%) weekly & $152(59 \%)$ \\
78 (30\%) monthly & $78(30 \%)$ \\
28 (11\%) quarterly & $28(11 \%)$ \\
\hline MPS planning horizon: & \\
173 (66\%) 1-6 months & $173(66 \%)$ \\
65 (25\%) 6-12 months & $65(25 \%)$ \\
23 (9\%) 12-24 months & $23(9 \%)$ \\
\hline &
\end{tabular}

\subsection{The survey instrument}

The questionnaire was developed in three phases. First, for all constructs, we sought to use and extend published scales as much as possible, though it was necessary to develop several new measures, all based on existing literature and our case study experience. APICS (2010) terminology and definitions were used because they are considered to be the most established, both in practice and academia. Second, to account for content validity, we discussed preliminary drafts of the questionnaire with academic researchers. Third, we pretested the questionnaire by conducting five pilot studies at different manufacturing organisations, which resulted in our making some minor modifications. Most variables were measured using perceptual scales developed from Likert-scale items, with values ranging from one to seven (Appendix A).

Participants were assured that their data would be kept confidential. Once the project's usefulness was described to them, respondents were motivated to provide accurate responses in expectation of being e-mailed summary analyses after all data were collected. We believe that this strategy partly reduced potential distortions in such subjective data. 
Full reference to this article: Jonsson, P. and Kjellsdotter Ivert, L. (2015). "Improving performance with sophisticated master production scheduling". International Journal of Production Economics, Vol. 168, pp. 118-130. D0I:10.1016/j.ijpe.2015.06.012

Planning environment complexity was measured using the following four scales: demand uncertainty (i.e., one item about random forecast variations), production uncertainty (i.e., two items on restrictions in available capacity and disruptions), supply uncertainty (i.e., two items on supply time and volume availability), and detail complexity (i.e., one item about the number of planning objects). All four scales were adapted from those in Bozarth et al. (2009) with some modifications, for the original scales were intended to measure supply chain complexity, whereas we examine a smaller part of supply chain complexity in studying only one planning process therein. To provide some perspective, Bozarth et al. (2009) used 12 scales to assess supply chain complexity, while we have used only four. Nevertheless, some particular scales used in this study (e.g., demand uncertainty and supply uncertainty) were those that also gauged effects on plant performance in Bozarth et al. (2009).

MPS maturity was measured using a three-item scale assessing activities, meetings, and integration. Earlier studies have emphasised the difficulty of measuring the maturity of a company's processes (Heinrich and Simchi-Levi, 2005), and as far as we know, no commonly employed measure of MPS maturity exists. Lockamy and McCormack (2004) authored one of the first published studies to examine process maturity in relation to supply chain management, while other studies have since focused on specific planning processes such as S\&OP when assessing process maturity (e.g., Grimson and Pyke, 2007; Lapide, 2005). Since the steps of MPS and S\&OP are similar in several ways (Jonsson and Mattsson, 2009), S\&OP maturity frameworks have been used as starting points for operationalisation. The framework suggested by Grimson and Pyke (2007) consists of five S\&OP dimensions, two of which-one, meeting and collaboration, and two, organisation — are primarily business processes. The third relates to assessment and improvement (i.e., measurement), while the last two (i.e., information technology and S\&OP plan integration) are information processes. In the operationalisation of MPS maturity, the dimensions of meeting and collaboration have been used, since our focus has been the business process, not the information process or assessment.

Sophistication of the MPS method was measured with a question listing six alternative MPS methods, each with a various level of sophistication. Tenhiälä's (2011) definition of capacity planning methods has inspired our development of the measure of the sophistication of the MPS method, though that study considers methods of MPS and of material requirement planning and input and output control, whereas we focus on MPS methods only. Respondents were given a description of each of the six planning method alternatives and asked to identify which best described the method used at their firms. Earlier studies of planning methods for production planning found this selftyping paragraph approach helpful (e.g. Tenhiälä, 2011). To consider the different methods' unique characteristics in the analysis, the variable of the sophistication of the MPS method was indicator dummy coded (Hair et al., 2010) in five categories. Since both Methods 5 and 6 represent highly sophisticated methods involving clear procedures, automation, and APS-supported, capacity-constrained planning; and since Method 6 represents quite a few (18) users, these two methods were combined into one category of highly sophisticated methods. With a total of 73 users, this category was set as the reference category and was excluded from the regression models. Method 1 (32 users), Method 2 (61 users), Method 3 (71 users), and Method 4 (52 users) were all commonly used methods and reflected relatively higher levels of method sophistication, yet nevertheless operated at a lower level than that of the reference category. These four categories were dummy coded, with code ' 1 ' representing method usage. 
Full reference to this article: Jonsson, P. and Kjellsdotter Ivert, L. (2015). "Improving performance with sophisticated master production scheduling". International Journal of Production Economics, Vol. 168, pp. 118-130. D0I:10.1016/j.ijpe.2015.06.012

MPS performance was measured using three scales: plan feasibility (i.e., two items regarding the extent to which production is based on the plan and the plan used as a frame for operational planning, inventory turnover rate (i.e., single item), and delivery service (i.e., single item). According to Becker and Gerhart (1996), 'The appropriate dependent variable will vary with the level of analysis, but in each case the focus should be on variables that have inherent meaning for the particular context'. Because the unit of analysis for this study is MPS, we argue that planning environment, process, and methods should directly impact the feasibility of the production plan and plant performance.

Performance criteria relating to the output of a process (i.e., production plan) are commonly used in production planning and scheduling research (Bozarth et al., 2009; de Snoo et al., 2011). At the same time, inventory turnover rate and delivery performance are variables that production planning and control processes are expected to impact (Jonsson and Mattsson, 2009; Tenhiälä, 2011). For measurements on plant performance, it is common to use perception-based measures by asking each respondent to compare his or her plant's performance with that of its competitors (e.g., Ahmad and Schroeder, 2003; Bozarth et al., 2009; Devaraj et al., 2004), which was done when accessing delivery service and inventory turnover rates.

Size and capacity flexibility were included in the analysis as control variables. Size was measured as the number of employees, whereas capacity flexibility - that is, the possibility of increasing and decreasing capacity—was measured with a single-item scale (see Appendix A).

\subsection{Measurement validity and reliability}

Five items were single-item measures (Appendix A). Bergkvist and Rossiter (2007) argue that single-item measures are acceptable when '(1) the object of the construct is "concrete singular", meaning that it consists of one object that is easily and uniformly imagined, and (2) the attribute of the construct is "concrete", again meaning it is easily and uniformly imagined'. In the present study, the construct object for most single-item measures was unambiguous. Each scale was evaluated for its construct validity and reliability via exploratory factor analysis (EFA), Cronbach's alpha tests, and bivariate correlation tests. It has been recommended that EFA be used for scales that are early in their development (Hurley et al., 1997), which was the case for all of our scales. Two factor analyses with varimax rotation were conducted: one for the independent items, and one for the plan feasibility items. Table 4 presents the results of the independent item factor analysis, while Table 5 provides descriptive and correlation statistics for each item. 
Full reference to this article: Jonsson, P. and Kjellsdotter Ivert, L. (2015). "Improving performance with sophisticated master production scheduling". International Journal of Production Economics, Vol. 168, pp. 118-130. DOI:10.1016/j.ijpe.2015.06.012

Table 4 Exploratory factor analysis, inter-item correlation, and Cronbach’s alpha of independent variables and constructs

\begin{tabular}{|c|c|c|c|c|}
\hline \multirow[t]{2}{*}{ Item } & \multicolumn{4}{|c|}{ Component } \\
\hline & 1 & 2 & 3 & 4 \\
\hline Demand uncertainty & -.06 & -.22 & .17 & .64 \\
\hline Detail complexity & .01 & .04 & -.07 & .85 \\
\hline Supply uncertainty: Item A & .08 & .90 & .04 & -.17 \\
\hline Supply uncertainty: Item B & .07 & .92 & -.02 & -.01 \\
\hline Production uncertainty: Item A & .00 & .00 & .87 & -.03 \\
\hline Production uncertainty: Item B & -.08 & .00 & .84 & .13 \\
\hline MPS maturity: Item A & .90 & .04 & .05 & -.03 \\
\hline MPS maturity: Item B & .88 & -.04 & -.02 & .02 \\
\hline MPS maturity: Item C & .56 & .30 & -.19 & -.06 \\
\hline Eigenvalue & 2.30 & 1.58 & 1.51 & 1.06 \\
\hline Reliability $(\alpha, r)$ & & & $r=.49$ & \\
\hline
\end{tabular}

Note: Principal component analysis with varimax rotation explained $71.66 \%$ of cumulative percentage variance. Values in boldface represent the factor loadings of each item on its intended construct. Cronbach's alpha $(\alpha)$ and inter-correlation $(r)$ values concern constructs based on items in boldface.

Table 5 Means, standard deviations, and bivariate correlations

\begin{tabular}{|c|c|c|c|c|c|c|c|c|c|c|c|c|c|c|c|}
\hline & Mean $(S D)$ & 1 & 2 & 3 & 4 & 5 & 6 & 7 & 8 & 9 & 10 & 11 & 12 & 13 & 14 \\
\hline $\mathrm{X}_{1}$ & $1.93(0.87)$ & & & & & & & & & & & & & & \\
\hline $\mathrm{X}_{2}$ & $4.29(1.55)$ & $-.14^{*}$ & & & & & & & & & & & & & \\
\hline $\mathrm{X}_{3}$ & $3.37(1.67)$ & -.10 & $.19 * *$ & & & & & & & & & & & & \\
\hline $\mathrm{X}_{4}$ & $5.04(1.79)$ & .04 & .09 & $.16^{* * *}$ & & & & & & & & & & & \\
\hline $\mathrm{X}_{5}$ & $3.22(1.53)$ & $-.19 * *$ & .09 & $.26^{* * *}$ & .11 & & & & & & & & & & \\
\hline $\mathrm{X}_{6}$ & $2.95(1.38)$ & $-.14^{*}$ & .06 & $.15^{* * *}$ & .06 & $.73^{* * *}$ & & & & & & & & & \\
\hline $\mathrm{X}_{7}$ & 3.67 (1.69) & $.07 *$ & .10 & -.11 & .00 & -.03 & .04 & & & & & & & & \\
\hline $\mathrm{X}_{8}$ & $3.93(1.51)$ & .00 & $-.14^{*}$ & $.18^{* * *}$ & .07 & .04 & .04 & $.49 * *$ & & & & & & & \\
\hline $\mathrm{X}_{9}$ & $4.95(1.68)$ & .09 & .00 & -.09 & -.02 & $-.12^{*}$ & $-.13^{*}$ & .01 & -.07 & & & & & & \\
\hline $\mathrm{X}_{10}$ & $4.77(1.80)$ & .04 & .05 & -.09 & .02 & -.07 & -.04 & -.06 & -.08 & $.70^{* * *}$ & & & & & \\
\hline $\mathrm{X}_{11}$ & $4.40(1.57)$ & .03 & -.07 & -.10 & -.07 & $-.24 * *$ & $-.25 * *$ & $-.14^{*}$ & $-.13^{*}$ & $.39 * *$ & $.30^{* * *}$ & & & & \\
\hline $\mathrm{X}_{12}$ & $5.13(1.28)$ & .05 & .08 & -.10 & -.01 & $-.27 * *$ & $-.21 * *$ & -.12 & $-.23^{* *}$ & $.38^{* * *}$ & $.28 * *$ & $.46^{* * *}$ & & & \\
\hline $\mathrm{X}_{13}$ & $5.40(1.34)$ & .06 & .12 & -.09 & -.11 & -.08 & -.03 & $-.12^{*}$ & -.08 & $.30^{* * *}$ & $.23 * *$ & $.33^{* *}$ & $.55 * *$ & & \\
\hline $\mathrm{X}_{14}$ & $5.31(1.06)$ & $.15^{*}$ & $.14^{*}$ & .00 & .05 & $-.27 * *$ & $-.19 * *$ & .02 & -.06 & $.25 * *$ & $.18^{* * *}$ & $.31^{* *}$ & $.30^{* * *}$ & $.24^{* *}$ & \\
\hline $\mathrm{X}_{15}$ & $4.41(1.02)$ & $.13^{*}$ & .11 & -.06 & .03 & $-.23 * *$ & $-.19 * *$ & .00 & -.03 & $.28^{* * *}$ & $.21 * *$ & $.28^{* *}$ & $.31^{* * *}$ & $.28^{* * *}$ & $.38^{* *}$ \\
\hline
\end{tabular}

The conceptual assumptions of factor analysis are that some underlying structure of the variables exists and that the sample is homogeneous with respect to the underlying factor structure. Some degree of multicollinearity is also desirable (Hair et al., 2010). Our underlying conceptual structure is strong, for the six first items in the independent item factor analysis represent four conceptually distinct constructs, all of which are related in measuring different aspects of planning environment complexity. The three last items for MPS maturity are not conceptually related to the first six. Though the sample represents manufacturing companies with various characteristics, we expect it to be homogeneous in terms of factor structure.

Each item loaded heavily onto one of the four single factors with minimal crossloading (Table 4). The three first factors were consistent with the underlying MPS maturity variable, the supply uncertainty variable, and the production uncertainty variable. The alpha value $(\alpha=.72)$ exceeded 0.65 for the three-item construct, which itself exceeds the suggested threshold value for new scales (Forza, 2002; Hair et al., 2010). The second and third constructs were two-item constructs, with high bivariate correlations between their intra-construct items ( $r=.73$ and $r=.49)$; the within- 
Full reference to this article: Jonsson, P. and Kjellsdotter Ivert, L. (2015). "Improving performance with sophisticated master production scheduling". International Journal of Production Economics, Vol. 168, pp. 118-130. D0I:10.1016/j.ijpe.2015.06.012

construct correlations of the items for these constructs were stronger than across constructs (Table 5), which further indicates discriminant validity. Two items formed the fourth factor, though the bivariate correlation between them was not high $(r=.19)$ and clearly not the strongest correlation for these items (Table 5). Since it was also difficult to conceptually define the items as a multi-item construct, these two items were used as single-item variables of demand uncertainty and detail complexity, largely in accordance with the original conceptualisation and survey instrument design. In the factor analysis of the plan feasibility items, the two items loaded on one factor with factor loadings of .88 and resulted in a two-item construct with a strong bivariate correlation between the items $(r=.55)$. These results suggest that the final measures of the constructs are reliable and have discriminant validity.

Some weak cross-loadings and correlations between items in different independent constructs surfaced. The strongest bivariate correlations between items in different independent variable constructs were demand uncertainty's $\left(\mathrm{X}_{3}\right)$ correlation with supply uncertainty item $\mathrm{A}\left(\mathrm{X}_{5}\right)$ (correlation coefficient: .26) and with production uncertainty item $\mathrm{A}\left(\mathrm{X}_{8}\right)$ (correlation coefficient: .18), as well as the two supply uncertainty items' $\left(\mathrm{X}_{5}-\mathrm{X}_{6}\right)$ and the two production uncertainty items' $\left(\mathrm{X}_{7}-\mathrm{X}_{8}\right)$ correlation with process maturity item $\mathrm{C}\left(\mathrm{X}_{11}\right)$ (correlation coefficients: .13-.25). We do not infer that these correlations indicate low discriminant validity, but instead inter-construct relations. For example, higher demand uncertainty can create supply and production uncertainties, while cross-functional cooperation in the MPS process can reduce supply and production uncertainty. These cross-construct item correlation coefficients are nevertheless not very high.

Analysis was conducted involving three hierarchical regression analyses with plan feasibility, inventory turnover rate, and delivery service as dependent variables and planning environment complexity, MPS maturity, sophistication of MPS method, and control variables as independent variables. The multicollinearity in regression models falls below the suggested threshold values (Hair et al., 2010) for all regression models (highest variance inflation factor value: 1.28) when all blocks of independent variables are entered. This further indicates that the significant correlations between single items across constructs have not resulted in any unacceptable multicollinearity.

\section{Findings and Discussion}

Three hierarchical regression analyses involving plan feasibility, inventory turnover rate, and delivery service as dependent variables were conducted. After control variables (i.e., size and capacity flexibility) were entered into the regression models, to test the incremental increase of the independent variables in $R^{2}$, these variables were entered in the regression models in three steps:

1. Planning environment complexity variables (i.e., demand uncertainty, production uncertainty, supply uncertainty, and detail complexity);

2. The MPS maturity variable; and

3. The sophistication of MPS method variables (i.e., four dummy variables). 
Full reference to this article: Jonsson, P. and Kjellsdotter Ivert, L. (2015). "Improving performance with sophisticated master production scheduling". International Journal of Production Economics, Vol. 168, pp. 118-130. DOI:10.1016/j.ijpe.2015.06.012

Table 6 Regressions for plan feasibility

\begin{tabular}{|c|c|c|c|c|c|c|c|c|}
\hline \multicolumn{9}{|c|}{ Dependent variable: Plan feasibility } \\
\hline \multirow[t]{2}{*}{ Independent variables } & \multicolumn{2}{|l|}{ Model 1} & \multicolumn{2}{|l|}{ Model 2} & \multicolumn{2}{|l|}{ Model 3} & \multicolumn{2}{|l|}{ Model 4} \\
\hline & Beta & $t$ value & Beta & $t$ value & Beta & $t$ value & Beta & $t$ value \\
\hline Step 1 & & & & & & & & \\
\hline Size & 0.09 & 1.42 & 0.06 & 0.95 & 0.04 & 0.78 & 0.04 & 0.72 \\
\hline Capacity flexibility & 0.14 & $2.17^{* *}$ & 0.14 & $2.33^{* *}$ & 0.11 & $1.87 *$ & 0.11 & $1.94 *$ \\
\hline Step 2 & & & & & & & & \\
\hline Demand uncertainty & & & -0.04 & -0.68 & -0.03 & -0.52 & -0.02 & -0.37 \\
\hline Production uncertainty & & & -0.15 & $-2.34 * *$ & -0.11 & $-1.93 *$ & -0.10 & $-1.83 *$ \\
\hline Supply uncertainty & & & -0.16 & $-2.51 * *$ & -0.09 & -1.49 & -0.06 & -1.10 \\
\hline Detail complexity & & & -0.06 & -0.92 & -0.06 & -1.09 & -0.02 & -0.42 \\
\hline Step 3 & & & & & & & & \\
\hline MPS maturity & & & & & 0.42 & $7.40^{* * *}$ & 0.41 & $7.34 * * *$ \\
\hline Step 4 & & & & & & & & \\
\hline MPS Method 1 & & & & & & & -0.20 & $-3.14^{* * *}$ \\
\hline MPS Method 2 & & & & & & & -0.22 & $-3.27 * * *$ \\
\hline MPS Method 3 & & & & & & & -0.11 & $-1.66^{*}$ \\
\hline MPS Method 4 & & & & & & & -0.12 & $-1.77 *$ \\
\hline Adjusted $R^{2}$ & .02 & & .06 & & .23 & & .27 & \\
\hline Changes in $R^{2}$ & & & & & & & & \\
\hline$F$ value of change in $R^{2}$ & $2.96 * *$ & & $3.95^{* * *}$ & & $54.70^{* * *}$ & & $3.78^{* * *}$ & \\
\hline
\end{tabular}

${ }^{*} p<.10,{ }^{* *} p<.05, * * * p<.01$

Table 7 Regressions for inventory turnover rate

Dependent variable: Plan feasibility

\begin{tabular}{|c|c|c|c|c|c|c|c|c|}
\hline Independent variables & Model 1 & & Model & & Model 3 & & Model & \\
\hline & Beta & $t$ value & Beta & $t$ value & Beta & $t$ value & Beta & $t$ value \\
\hline $\begin{array}{l}\text { Step } 1 \\
\text { Size } \\
\text { Capacity flexibility } \\
\text { Step } 2 \\
\text { Demand uncertainty } \\
\text { Production uncertainty } \\
\text { Supply uncertainty } \\
\text { Detail complexity } \\
\text { Step } 3 \\
\text { MPS maturity } \\
\text { Step } 4 \\
\text { MPS Method } 1 \\
\text { MPS Method } 2 \\
\text { MPS Method } 3 \\
\text { MPS Method } 4\end{array}$ & $\begin{array}{l}0.17 \\
0.14\end{array}$ & $\begin{array}{l}2.68^{* * *} \\
2.26^{* *}\end{array}$ & $\begin{array}{l}0.13 \\
0.16 \\
\\
-0.02 \\
0.02 \\
-0.22 \\
0.02\end{array}$ & $\begin{array}{l}1.96^{*} \\
2.44^{* *} \\
\\
-0.34 \\
0.35 \\
-3.35^{* * *} \\
0.37\end{array}$ & $\begin{array}{l}0.12 \\
0.14 \\
\\
-0.02 \\
0.04 \\
-0.17 \\
0.02 \\
\\
0.26\end{array}$ & $\begin{array}{l}1.86^{*} \\
2.24^{* *} \\
\\
-0.27 \\
0.68 \\
-2.67^{* * *} \\
0.28 \\
\\
4.11^{* * *}\end{array}$ & $\begin{array}{l}0.12 \\
0.14 \\
\\
\\
-0.02 \\
0.04 \\
-0.17 \\
0.02 \\
\\
\\
\\
0.24 \\
\\
\\
-0.03 \\
-0.04 \\
0.02 \\
-0.08\end{array}$ & $\begin{array}{l}1.84^{*} \\
2.24^{* *} \\
\\
-0.24 \\
0.67 \\
-2.60^{* * *} \\
0.24 \\
\\
3.90^{* * *} \\
\\
-0.47 \\
-0.46 \\
0.24 \\
-1.15\end{array}$ \\
\hline $\begin{array}{l}\text { Adjusted } R^{2} \\
\text { Changes in } R^{2} \\
F \text { value of change in } R^{2}\end{array}$ & $\begin{array}{l}.04 \\
5.28^{* * *}\end{array}$ & & $\begin{array}{l}.07 \\
.03 \\
3.05^{* *}\end{array}$ & & $\begin{array}{l}.13 \\
.06 \\
16.86^{* * *}\end{array}$ & & $\begin{array}{l}.13 \\
.00 \\
0.56\end{array}$ & \\
\hline
\end{tabular}

$F$ value of change in $R^{2}$ 
Full reference to this article: Jonsson, P. and Kjellsdotter Ivert, L. (2015). "Improving performance with sophisticated master production scheduling". International Journal of Production Economics, Vol. 168, pp. 118-130. DOI:10.1016/j.ijpe.2015.06.012

Table 8 Regressions for delivery service

\begin{tabular}{|c|c|c|c|c|c|c|c|c|}
\hline \multicolumn{9}{|c|}{ ependent variable: Pl } \\
\hline & Beta & $t$ value & Beta & $t$ value & Beta & $t$ value & $\frac{1 \text { Model } 4}{\text { Beta }}$ & $t$ value \\
\hline Step 1 & & & & & & & & \\
\hline Size & 0.18 & $2.86 * * *$ & 0.13 & $2.05^{* *}$ & 0.12 & $1.97^{* *}$ & 0.12 & $1.92 *$ \\
\hline Capacity flexibility & 0.17 & $2.67 * * *$ & 0.17 & $2.61^{* *}$ & 0.15 & $2.41^{* *}$ & 0.15 & $2.41^{* *}$ \\
\hline Step 2 & & & & & & & & \\
\hline Demand uncertainty & & & 0.02 & 0.32 & 0.03 & 0.45 & 0.03 & 0.52 \\
\hline Production uncertainty & & & -0.02 & -0.28 & 0.00 & & 0.00 & 0.08 \\
\hline Supply uncertainty & & & -0.23 & $-3.67 * * *$ & -0.18 & $-2.90^{* * *}$ & -0.17 & $-2.72 * * *$ \\
\hline Detail complexity & & & 0.07 & 1.12 & 0.06 & & 0.06 & 0.94 \\
\hline Step 3 & & & & & & & & \\
\hline MPS maturity & & & & & 0.26 & $4.28^{* * *}$ & 0.27 & $4.51^{* * *}$ \\
\hline Step 4 & & & & & & & & \\
\hline MPS Method 1 & & & & & & & 0.04 & 0.68 \\
\hline MPS Method 2 & & & & & & & -0.27 & $-3.85 * * *$ \\
\hline MPS Method 3 & & & & & & & -0.05 & -0.67 \\
\hline MPS Method 4 & & & & & & & -0.10 & -1.40 \\
\hline Adjusted $R^{2}$ & .04 & & .08 & & .14 & & .20 & \\
\hline Changes in $R^{2}$ & & & & & & & & \\
\hline F-value of change in $R^{2}$ & $6.64 * * *$ & & $3.59 * * *$ & & $18.35 * * *$ & & $5.27 * * *$ & \\
\hline
\end{tabular}

Results of the regression models appear in Tables 6-8. Table 6 regards the plan feasibility models, while Tables 7 and 8 correspond to the plant performance models. Model 1 in each table represents the control variables. These three models explain 2 $4 \%$ of performance variance. The plant performance models had the highest $R^{2}$, and all models were significant $(p<.05)$.

\subsection{The importance of planning environment complexity (Hypothesis 1)}

As shown in all three tables, as pertains to Model 2, entering the complexity variables resulted in significantly improved models, represented by significant $F$ values of the change in $R^{2}$. All $R^{2}$ values were nevertheless quite low in the models, at values from 6-8\%. Supply uncertainty exerted significant influence on all three dependent variables (i.e., plan feasibility, inventory turnover rate, and delivery service), and production uncertainty was significant for plan feasibility. These results provide support for Hypothesis 1, especially for the variable of supply uncertainty.

Results also indicate that it is difficult to conduct MPS when material is not delivered on time or in the right quality, as well as when unplanned disturbances and capacity restriction in the production process are common. According to Vieira and Favaretto (2006), literature addressing MPS does not consider limited available capacity to any significant extent, which is problematic given that capacity in real production environments is often limited. Both production and supply uncertainty are connected to available capacity, and our results suggest that capacity restriction needs to receive greater focus both in literature addressing MPS and in practice.

Demand uncertainty and detail complexity did not significantly influence MPS performance. Demand uncertainty is connected to required capacity and is an important element in developing production plans. The sample primarily contained cases with low or medium demand uncertainty, though the variable was never very high, which might explain why demand uncertainty did not significantly influence MPS performance. The detail complexity means were higher in the sample, though the number of planning objects nevertheless did not constitute a major problem. Our results thus suggest that dynamic complexity creates more difficulties than detail complexity, a finding also 
Full reference to this article: Jonsson, P. and Kjellsdotter Ivert, L. (2015). "Improving performance with sophisticated master production scheduling". International Journal of Production Economics, Vol. 168, pp. 118-130. DOI:10.1016/j.ijpe.2015.06.012

identified by Bozarth et al. (2009) in their study of the impact of supply chain complexity on plant performance.

\subsection{The importance of MPS process maturity (Hypothesis 2)}

Entering the variable of MPS maturity into Model 3 resulted in an incremental improvement in $R^{2}$ over that of Model 2 (6\% versus $17 \%, p<.01$ ), and $13-17 \%$ of the performance variation could be explained after the variable of MPS maturity was added. This finding supports Hypothesis 2. Notably, all negative impacts of planning environment complexity diminished when MPS maturity was entered into the plan feasibility and delivery service models. In the inventory turnover rate model, two of the four complexity variables drop in terms of negative impact; these changes are also especially significant in the plan feasibility model. In accordance with Barron and Kenny's (1986) approach to testing mediation, we thus conclude that MPS process maturity mediates how planning environment complexity affects performance. Some of this effect was already implied by the significant correlations between individual items across constructs (Table 5), though becomes further explained in the regression.

Studies of MPS usually focus on technical aspects such as planning parameters and MPS methods (e.g., Chu, 1995; Lin and Krajewski, 1992; Robinson et al., 2008; Vieira and Favaretto, 2006; Zhao et al., 2001). Our results, however, reveal the importance of conducting MPS in consecutive, repetitive steps in which key persons participate in meetings and cooperation among functions is active and efficient. The importance of process maturity in relation to performance has been identified in studies of S\&OP, demand management, and production scheduling (de Snoo et al., 2011; Grimson and Pyke, 2007; Heinrich and Simchi-Levi, 2005). The process dimension is less emphasised in research addressing MPS, though our findings indicate that the maturity of the process should be as important in MPS as in other planning and scheduling processes. The finding that entering MPS maturity into the regression reduces the negative impact of planning environment complexity, especially in terms of production and supply uncertainties, is especially interesting, for it implies that a structured, mature MPS process can reduce the negative effects of complex planning environments. This finding indicates that the MPS process maturity affects performance both directly and indirectly in light of planning environment complexity.

\subsection{The importance of the sophistication of the MPS method (Hypothesis 3)}

In Model 4, the variables of the sophistication of the MPS method (i.e., four dummy variables representing the use of the four less sophisticated MPS methods) were entered. This addition increased $R^{2}$ by 0,4 , and $6 \%$ in the respective models. The $F$ value of the change in $R^{2}$ was significant ( $p<.01$ ) in the plan feasibility and delivery service models, yet had no significant impact in the inventory turnover rate model. In the plan feasibility model, MPS Methods 1-4 exerted a significant negative effect relative to the reference variable (i.e., the combined variable of Methods 5 and 6), in which Methods 1 and 2 had the strongest, most significant negative effect. In the delivery service model, MPS Method 2 bore a strong and significant $(p<.01)$ negative effect on performance. Hypothesis 3 is consequently supported in terms of plan feasibility, as well as partly in terms of one of the two plant performance measures. The negative impact of planning environment complexity became further reduced when variables of the sophistication of the MPS method were entered in the models. 
Full reference to this article: Jonsson, P. and Kjellsdotter Ivert, L. (2015). "Improving performance with sophisticated master production scheduling". International Journal of Production Economics, Vol. 168, pp. 118-130. D0I:10.1016/j.ijpe.2015.06.012

Results indicate that using a sophisticated MPS method (e.g., an APS systemsupported method for capacity-constrained planning with heuristics or optimisation) in favour of a less sophisticated method results in production plans that to a greater extent are considered possible guides for production and that to an even greater extent are used as frameworks for operational planning. Using the most sophisticated methods thus seems to induce a focus on the method, thereby motivating personnel to use production plans more than before. The weakest commitment to production plans is given to less sophisticated methods, in which the final production plan is based on a forecasted demand and delivery plan without considering available capacity, current and targeted inventory levels, or sizes of order backlog, as well as when available capacity is compared and manually balanced with required capacity without considering current and targeted inventory levels or sizes of order backlog.

Our findings show similar, though less clear, relationships between the sophistication of the MPS method and plant performance, particularly after considering the effect of planning environment complexity and process maturity. Here, the use of the simplest manual MPS method for capacity balancing (Method 2) —in which available capacity is compared and manually balanced with required capacity, without considering current and targeted inventory levels or sizes of order backlog - bears a strong, significantly negative effect on delivery service. However, due to the lack of significance of MPS method in the inventory turnover rate model, the overall effect of the sophistication of the MPS method on plant performance remains somewhat unclear.

Tenhiälä (2011) and Jonsson and Mattsson (2003) stress that context is important in successfully using planning methods and for realising the positive effects had by using sophisticated planning methods. Our results show that the sophistication of the MPS method - a context-independent variable - may generally affect performance, which is in accordance with the case-based study of Ivert and Jonsson (2014), which revealed that investment in an APS system resulted in higher commitment to the plan, even though important conditions in the organisation and contextual fit were not in place. In particular, our findings suggest that using an APS system supports capacity-constrained planning with heuristics or optimisation and increases the feasibility of plans and that using the most simple, manual MPS methods for capacity-constrained planning-which does not consider current and targeted performance-bears a direct negative effect on delivery service, regardless of planning environment complexity or MPS maturity. Our findings consequently indicate that considering capacity constraints requires highly sophisticated method support. Still, the least sophisticated MPS method, which stipulates manual planning without considering capacity, did not have a comparably significant negative effect in the delivery service model. This finding indicates that manual planning without considering available capacity does not pose a general negative effect on plant performance.

That the sophistication of the MPS method contributes to reducing the negative impact of planning environment complexity, after the effect of MPS process maturity is considered, indicates that method sophistication relates to context via the mediating effects of complex planning environments. This indication is not strong, but in accordance with Baron and Kenny (1986) signals that highly sophisticated MPS methods reduce the negative effects on dependent variables. Clearly, MPS process maturity and the sophistication of the MPS method not only directly affect plan feasibility, delivery service, and inventory turnover rate, but also indirectly affect performance by mediating the negative effects of planning environment complexity. 
Full reference to this article: Jonsson, P. and Kjellsdotter Ivert, L. (2015). "Improving performance with sophisticated master production scheduling". International Journal of Production Economics, Vol. 168, pp. 118-130. DOI:10.1016/j.ijpe.2015.06.012

\section{Conclusions}

Despite formidable interest in and the high expectations of sophisticated planning methods, not much has been written about how well different planning methods perform in reality. This situation has been a problematic one, and multiple researchers have stressed that the academic community needs to play a far more active role in studying the performance of sophisticated methods in practice.

The findings of this study show that the most sophisticated MPS methods result in the most feasible plans, as well as that using less sophisticated, manual MPS methods for capacity-constrained planning negatively affects delivery service performance after planning environment complexity and MPS process maturity are considered. For decades, literature has identified the importance of context and the need to adjust planning methods to the unique planning environment of a company in order to boost performance (e.g., Berry and Hill, 1992; Jonsson and Mattsson, 2003; Kaipia and Holmström, 2007; Olhager and Selldin, 2007; Tenhiälä, 2011). Our results, however, suggest that the use of MPS methods of various levels of sophistication bears a general, direct effect on performance regardless of context. Our analysis also nevertheless indicates that the sophistication of the MPS method is context-related given its mediating effect in complex planning environments. In short, greater sophistication reduces the negative effects of complex environments on performance.

We also find that planning environment and process maturity influence MPS performance. In particular, supply uncertainty and production uncertainty make it difficult for personnel to make good use of the production plan. Supply uncertainty is most critical, owing to its negative influence on plant performance (i.e., service level and inventory turnover rates). In our study, MPS process maturity influenced all performance models and was the independent variable that exerted the strongest effect on MPS performance.

An important finding of our study is that MPS process maturity and the sophistication of the method not only bear direct effects on performance, but also indirectly affect performance by way of mediating the effects of planning environment complexity. Previous studies have not clearly shown how sophisticated methods generate or manage complexity. In response, our study shows that sophisticated methods can better accommodate complexity and reduce the negative impact of complexity than less sophisticated methods. Since our empirical support is not exceptionally strong, our observation carves out space for future studies focusing on the indirect effect of sophisticated planning methods on performance by moderating the effects of other variables.

Another interesting observation from the study is the differentiation of MPS methods regarding capacity-constrained planning. Our findings show that the most sophisticated methods are required for capacity-constrained planning, yet that manual planning that does not consider capacity does not necessarily negatively affect performance.

In our analysis, MPS performance was measured on two levels: the output of MPS (i.e., plan feasibility) and the effect of MPS (i.e., plant performance). Findings clarify significant direct relationships between plan feasibility and the independent variables, since entering all blocks of independent variables resulted in significantly improved $R^{2}$. The same is true for the delivery service (i.e., plant performance) model, however with somewhat lower $R^{2}$ values. In sum, all three hypotheses are verified for these two dependent variables. The model with inventory turnover rate (i.e., plant performance) as 
Full reference to this article: Jonsson, P. and Kjellsdotter Ivert, L. (2015). "Improving performance with sophisticated master production scheduling". International Journal of Production Economics, Vol. 168, pp. 118-130. D0I:10.1016/j.ijpe.2015.06.012

its dependent variable shows generally lower $R^{2}$ values than the other two dependent variables, and entering the last block of independent variables (i.e., the sophistication of the MPS method) does not produce a significantly improved model. The inventory turnover rate model, consequently, weakens the results of this study.

The study clearly shows that choosing a sophisticated MPS method is critical to plan feasibility, though it is less clear whether it has a generally important impact on plant performance. More detailed, context-related studies are thus needed to further analyse this relationship. Our study also reveals the difficulty of focusing solely on plant performance measures when investigating the effects of production planning-related factors, thereby supporting the conclusion that output should be separated from effects when assessing performance (e.g., Banker et al., 2006). Many studies that investigate the effect of business processes on performance have examined plant performance only, whereas our study identifies the need to assess performance much closer to the process.

This study contributes to MPS-related literature by analysing which factors influence MPS performance. Previous studies of MPS have focused on technical aspects, including planning parameters and methods for development of the production plan, while aspects connected to the process and actual performance of the methods in practice are usually forgotten. The present study contributes to MPS in practice by clarifying how MPS performance can be improved. Sophisticated methods in particular increase plan feasibility, though the use of overly simple methods can also negatively impact delivery service, no matter the context. Establishing a process with clearly defined activities that involves personnel from different functions in the process is a top priority for improving performance. The planning environment is not the most important variable to consider when designing MPS processes, though it is crucial to include restrictions and limitations on capacity while developing the production plan.

There are some limitations in this study regarding its data collection and analysis. In the sample, few companies used the most sophisticated MPS method (i.e., Method 6). Therefore, we combined the two most sophisticated methods in our empirical analysis. In further research, it would be interesting to focus on users of the most sophisticated APS system-supported MPS method in order to understand the possible value of using such methods and to determine what is needed in order to make the best use of the methods. It would also be interesting to more deeply study the performance effect of MPS Method 1 in various contexts as a means to develop an understanding of when and how this method may be sufficient for use. For example, are there situations in which this method outperforms the most sophisticated MPS methods (i.e., Methods 5 and 6)?

Though the measures in the survey were newly developed and the tests indicated appropriate validity, the survey design and use of EFA for the validity tests could also be considered to pose a limitation in comparison to using a more conservative confirmatory factor analysis approach. The complexities of most sampled manufacturing companies were not very high, which may be a reason why the dimensions of complexity did not influence the results to a large extent. In further research, it could be useful to focus on companies with high demand uncertainty to investigate its impact on MPS methods in improving MPS performance. It would also be useful to further investigate the role of detail complexity in MPS performance when using different MPS methods.

In this study, detail complexity was defined rather narrowly as the number of planning objects included in the production plan. In further research, the term could be expanded to also encompass, for example, the number of work centres in the production process and the number of items and products. 
Full reference to this article: Jonsson, P. and Kjellsdotter Ivert, L. (2015). "Improving performance with sophisticated master production scheduling". International Journal of Production Economics, Vol. 168, pp. 118-130. DOI:10.1016/j.ijpe.2015.06.012

The results also emphasise the importance of MPS maturity in securing high MPS performance. Future studies should thus dig deeper into those dimensions to elucidate their roles in MPS performance, as well as into the role of MPS maturity in the success of MPS methods with different levels of sophistication.

\section{References}

Ahmad, S., Schroeder, R.G., 2003. The impact of human resource management practices on operational performance: Recognizing country and industry differences. Journal of Operations Management, 21 (1), 19-43.

APICS, 2010. Using information technology to enable supply chain management. Alexandria, VA: APICS Certified Supply Chain Professional Learning System.

APICS, 2012. CPIM II: Master planning of resources (MPR): Participants' guide. Alexandria, VA: APICS Certified Supply Chain Professional Learning System.

Banker, R.D, Bardhan, I.R, Chang H., Lin S., 2006. Plant information systems, manufacturing capabilities and plant performance. MIS Quarterly, 30 (2), 315-337.

Bakhrankova, B., 2010. Decision support system for continuous production. Industrial Management \& Data Systems, 110 (4), 591-610.

Baron, R.M., Kenny, D.A., 1986. The moderator-mediator variable distinction in social psychological research: Conceptual, strategic, and statistical considerations. Journal of Personality and Social Psychology, 51 (6), 1173-1182.

Becker, B., Gerhart, B., 1996. The impact of human resource management on organizational performance: Progress and prospect. Academy of Management Journal, 39 (4), 779-801.

Berglund, M., Karltun, J., 2007. Human, technological and organizational aspects influencing the production scheduling process. International Journal of Production Economics, 110 (1/2), 160-174.

Berry, W.L., Hill, T., 1992. Linking system to strategy. International Journal of Operations \& Production Management, 12 (10), 3-15.

Bergkvist, L. Rossiter, J.R., 2007. The predictive validity of multiple-item versus single-item measures of the same construct. Journal of Marketing Research, 44 (2), 175-184.

Bozarth, C., Warsing, D.P., Flynn, B.B., Flynn, E.J., 2009. The impact of supply chain complexity on manufacturing plant performance. Journal of Operations Management, 27 (1), 78-93.

Carvalho, A.N., Scavarda, L.F., Lustosa, L.J., 2014. Implementing finite capacity production scheduling: Lessons from a practical case. International Journal of Production Research, 52 (4), 1215-1230.

Chen, K., Ji. P., 2007. A mixed integer programming model for advanced planning and scheduling (APS). European Journal of Operation Research, 181 (1), 515-522.

Chu, C.K.S., 1995. A mathematical programming approach towards optimized master production scheduling. International Journal of Production Economics, 38 (2/3), 269-279.

de Bruin, T., Rosemann, M., 2005. Towards a business process management maturity model. ECIS 2005 Proceedings of the Thirteenth European Conference on Information Systems, 26-28 May 2005, Regensburg, Germany. 
Full reference to this article: Jonsson, P. and Kjellsdotter Ivert, L. (2015). "Improving performance with sophisticated master production scheduling". International Journal of Production Economics, Vol. 168, pp. 118-130. DOI:10.1016/j.ijpe.2015.06.012

de Kok, A., Graves, S., 2003. Handbook in operations research \& management science, vol. 11: Supply chain management: Design, coordination \& operation. Amsterdam: Elsevier.

de Snoo, C., van Wezel, W., Jorna, R.J., 2011. An empirical investigation of scheduling performance criteria. Journal of Operations Management, 29 (3), 181-193.

Devaraj, S., Hollingworth, D.G., Schroeder, R.G., 2004. Generic manufacturing strategies and plant performance. Journal of Operations Management, 22 (3), 313333.

Entrup, M.L., 2005. Advanced planning in fresh food industries. Berlin: PhysicaVerlag/Springer.

Fisher, D.M., 2004. The business process maturity model: A practical approach for identifying opportunities for optimization. Available at: http://ww.w.bptrends.com/publicationfiles/1004\%20ART\%20BP\%20Maturity\%20Model\%20-\%20Fisher.pdf (Accessed 2 May 2015).

Fleischmann, B., Meyr, H., 2003. Planning hierarchy, modeling and advanced planning systems. In: de Kok, A.G., Graves, S.C. (Eds). Handbooks in Operations Research and Management Science. Amsterdam: Elsevier.

Forza, C., 2002. Survey research in operations management: A process-based perspective. International Journal of Operations \& Production Management, 22 (2), 152-194.

Grimson, J., Pyke, D., 2007. Sales and operations planning: An exploratory study and framework. International Journal of Logistics Management, 18 (3), 322-346.

Günter, H.O., 2005. Supply chain management and advanced planning systems: A tutorial. In Günter, H.O., Mattfeld, D., Suhl, L. (Eds). Supply chain management and logistics: Optimization, simulation, decision support. Physica: Heidenberg, 3-40.

Hair, J., Black, W., Babin, B., Anderson, A., 2010. Multivariate data analysis: A global perspective. London: Pearson.

Heinrich, C.E., Simchi-Levi, D., 2005. Do IT investments really pay off? Supply Chain Management Review, 9 (9), 22-29.

Hill, T., 1993. Manufacturing strategy: The strategic management of the manufacturing function. London: Macmillan.

Hurley, A.E., Scandura, T.A., Schriesheim, C.A., Brannick, M.T., Seers, A., Vandenberg, R.J., Williams, L.J., 1997. Exploratory and confirmatory factor analysis: Guidelines, issues, and alternatives. Journal of Organizational Behavior, 18, 667-683.

Hvolby, H.A., Steger-Jensen, S.J., 2010. Technical and industrial issues of advanced planning and scheduling (APS) systems. Computers in Industry, 61 (9), 845-851.

Ivert, L.K., Jonsson, P., 2010. The potential benefits of advanced planning and scheduling systems in sales and operations planning. Industrial Management \& Data Systems, 110 (5), 659-681.

Ivert, L.K., Jonsson, P., 2011. Problems in the onward and upward phase of APS system implementation: Why do they occur? International Journal of Physical Distribution \& Logistics Management, 41 (4), 343-363.

Ivert, L.K., Jonsson, P., 2014. When should advanced planning and scheduling systems be used in sales and operations planning? International Journal of Operations \& Production Management, 34 (10), 1338-1362.

Jackson, S., MacCarthy, B.L., Wilson, J.R., 2004. A new model of scheduling in manufacturing: Tasks, roles, and monitoring. Human Factors, 46 (3), 533-550. 
Full reference to this article: Jonsson, P. and Kjellsdotter Ivert, L. (2015). "Improving performance with sophisticated master production scheduling". International Journal of Production Economics, Vol. 168, pp. 118-130. DOI:10.1016/j.ijpe.2015.06.012

Jacobs, R., Whybark, C., Berry, W., Vollmann, T., 2011. Manufacturing planning and control for supply chain management. New York: McGraw-Hill.

Jonsson, P., 2008. Exploring problems related to the material planning user environment. International Journal of Production Economics, 113 (1), 383-400.

Jonsson, P., Kjellsdotter, L., Rudberg, M., 2007. Applying advanced planning systems for supply chain planning: Three case studies. International Journal of Physical Distribution \& Logistics Management, 37 (10), 816-834.

Jonsson, P., Mattsson, S.-A., 2003. The implication of fit between planning environment and manufacturing planning and control methods. International Journal of Operations \& Production Management, 23 (8), 872-900.

Jonsson, P., Mattsson, S.-A., 2008. Inventory management practices and their impact on perceived planning performance. International Journal of Production Research, 46 (7), 1787-1812.

Jonsson, P., Mattsson, S.-A., 2009. Manufacturing planning and control. London: McGraw-Hill.

Kaipia, R., Holmström, J., 2007. Selecting the right planning approach for a product. Supply Chain Management, 12 (1), 2-13

Kreipl, S., Dickersbach, J.D., 2008. Scheduling coordination problems in supply chain planning. Annals of Operations Research, 161 (1), 103-123.

Lapide, L., 2005. Sales and operations planning: Part II: Enabling technology. The Journal of Business Forecasting, 24 (1), 13-16.

Lin, C., Hwang, S.-L., Wang, M.-Y., 2007. A reappraisal on advanced planning and scheduling systems. Industrial Management \& Data Systems, 107 (8), 1212-1226.

Lin, N-P., Krajewski, L., 1992. A model for master production scheduling in uncertain environments. Decisions Science, 23 (4), 839-860.

Lockamy, A., Childerhouse, P., Disney, S.M., Towill, D.R., 2008. The impact of process maturity and uncertainty on supply chain performance: An empirical study. International Journal of Manufacturing Technology and Management, 15 (1), 12-27.

Lockamy, A., McCormack, K., 2004. The development of a supply chain management process maturity model using the concepts of business process orientation. Supply Chain Management, 9 (4), 272-278.

Mula, J., Poler, R., Garcia-Sabater, Lario, F. C., 2006. Models for production planning under uncertainty: A review. International Journal of Production Economics, 103 (1), 271-285.

Olhager, J., Selldin. E., 2003. Enterprise resource planning survey of Swedish manufacturing firms. European Journal of Operational Research, 146 (2), 365-373.

Olhager, J., Selldin, E. 2007. Manufacturing planning and control approaches: Market alignment and performance. International Journal of Production Research, 45 (6), 1469-1484.

Oliva, R., Watson, N., 2011. Cross-functional alignment in supply chain planning: A case study of sales and operations planning. Journal of Operations Management, 29 (5), 434-448.

Reuter, B., 2005. Demand planning of styrene plastic. In: Stadtler, H., Kilger, C. (Eds). Supply chain management and advanced planning: Concepts, models, software and case studies. 4th ed. Berlin: Springer.

Robinson, P.E., Sahlin, F., Gao, L., 2008. Master production schedule time interval strategies in make-to-order supply chains. International Journal of Production Research, 46 (7), 1933-1954. 
Full reference to this article: Jonsson, P. and Kjellsdotter Ivert, L. (2015). "Improving performance with sophisticated master production scheduling". International Journal of Production Economics, Vol. 168, pp. 118-130. DOI:10.1016/j.ijpe.2015.06.012

Rudberg, M., Thulin, J., 2009. Centralised supply chain master planning employing advanced planning systems. Production Planning \& Control, 20 (2), 158-167.

Schroeder, R.G., Anderson, J.C., Tupy, S.E., White E.W., 1981. A study of MRP benefits and costs. Journal of Operations Management, 2 (1), 1-9.

Setia, P., Sambamurthy, V, Closs, D.J. 2008. Realizing business value of agile IT applications: Antecedents in the supply chain network. Information Technology and Management, 9 (1), 5-19.

Soares, M., Vieira, G., 2009. A new and multi-objective optimization method for master production scheduling problems based on genetic algorithm. International Journal of Advanced Manufacturing Technology, 41 (5/6), 549-567.

Stadtler, H., Kilger, C., 2010. Supply chain management and advanced planning: Concepts, models, software and case studies. Berlin: Springer Verlag.

Tenhiälä, A., 2011. Contingency theory of capacity planning: The link between process types and planning methods. Journal of Operations Management, 20 (1/2), 65-77.

Thomé, T.A.M, Scavarda, L.F, Fernandez, N.S., Scavarda, A.J., 2012. Sales and operations planning: A research synthesis. International Journal of Production Economics, 138 (1), 1-13.

Tuomikangas, N. and Kaipia, R., 2014. A coordination framework for sales and operations planning (S\&OP): Synthesis from the literature. International Journal of Production Economics, 154, 243-262.

Vieira, G.E., Favaretto, F., 2006. A new and practical heuristic for master production scheduling creation. International Journal of Production Research, 44 (18/19), 36073627.

Wagner, M., Meyer, H., 2005. Food and beverages. In: Stadtler, H., Kilger, C. (Eds). Supply chain management and advanced planning: Concepts, models, software and case studies. Berlin: Springer Verlag.

Wiers, V.C.S., 2009. The relationship between shop floor autonomy and APS implementation success: Evidence from two cases. Production Planning \& Control, 20 (7), 576-585.

Yeung, K., Zhou, H., Yeung, A., Cheng, T.C.E., 2012. The impact of third-party logistics providers' capabilities on exporters' performance. International Journal of Production Economics, 135, 741-753.

Zhao, X., Xie, J., Joang, Q., 2001. Lot-sizing rule and freezing the master production schedule under capacity constraint and deterministic demand. Production and Operations Management, 10 (1), 45-67.

Zhou, H., Leong, K., Jonsson, P. and Sum, C-C., 2009. A comparative study of advanced manufacturing technology and manufacturing infrastructure investments in Singapore and Sweden. International Journal of Production Economics, 120 (1), 4253. 
Full reference to this article: Jonsson, P. and Kjellsdotter Ivert, L. (2015). "Improving performance with sophisticated master production scheduling". International Journal of Production Economics, Vol. 168, pp. 118-130. DOI:10.1016/j.ijpe.2015.06.012

\section{Appendix A: Measurement Scales}

\section{Sophisticated MPS methods}

Which one of the following six options correspond best to how your company or department establishes and develops production plans?

1. No consideration of capacity: The final production plan is based on the forecasted demand and delivery plan without considering available capacity, current and targeted inventory levels, or sizes of order backlog. (MPS method 1: $0=$ Not using, $1=$ Using)

2. Estimated balancing: Available capacity is compared and manually balanced with required capacity in order to produce the final production plan. Current and targeted inventory levels or sizes of order backlog are not taken into consideration. (MPS method 2: $0=$ Not using, $1=$ Using)

3. Estimated balancing with goal: Available capacity is compared and manually balanced with required capacity. Current and targeted inventory levels or sizes of order backlog are taken into consideration. (MPS method 3: 0 = Not using, 1 = Using)

4. Balancing with the help of system support: Capacity and inventory levels sizes of order backlog are taken into consideration. A system support is used to balance available capacity with required capacity and to analyse which products and/or customer orders form the load for a given period. (MPS method 4: $0=$ Not using, $1=$ Using)

5. Capacity levelling: Simple rules (i.e., heuristics) for considering available capacity and inventory levels/sizes of order backlog are used.

6. Optimal balancing: Optimisation is used that takes into consideration available capacity and goals for manufacturing costs, revenues, and tied-up capital.

\section{Control variables}

\begin{tabular}{|l|l|}
\hline Measure & Survey item \\
\hline Firm size & How many employees work at the plant? \\
& $\mathbf{1})<100$ \\
2) $100-300$ \\
3) $301-1,000$ \\
4) $>1,000$
\end{tabular}

\section{Planning environment complexity}

\begin{tabular}{|l|l|}
\hline Measure & Survey item \\
\hline $\begin{array}{l}\text { Demand } \\
\text { uncertainty }\end{array}$ & $\begin{array}{l}\text { The demand used as the input in the production plan is characterised by large random } \\
\text { variations. (1: Strongly disagree, 7: Strongly agree) }\end{array}$ \\
\hline $\begin{array}{l}\text { Production } \\
\text { uncertainty }\end{array}$ & $\begin{array}{l}\text { Average of the following items: } \\
\text { A: It is very common with unplanned disturbances in the production process } \\
\text { affecting the available capacity. (1: strongly disagree, 7: strongly agree) } \\
\text { B: It is very common with restrictions in available capacity. (1: Strongly disagree, 7: } \\
\text { Strongly agree) }\end{array}$ \\
\hline $\begin{array}{l}\text { Supply } \\
\text { uncertainty }\end{array}$ & 8 -Average of the following items: \\
\hline
\end{tabular}


Full reference to this article: Jonsson, P. and Kjellsdotter Ivert, L. (2015). "Improving performance with sophisticated master production scheduling". International Journal of Production Economics, Vol. 168, pp. 118-130. DOI:10.1016/j.ijpe.2015.06.012

\begin{tabular}{|l|l|}
\hline \multirow{1}{*}{$\begin{array}{l}\text { To what extent are the following statements regarding the suppliers' ability to deliver } \\
\text { at the right time and with the right quantity accurate? }\end{array}$} \\
$\begin{array}{l}\text { A: The prerequisites for receiving material needed to produce products stated in the } \\
\text { production plan at the right time are good. (1: Strongly disagree, 7: Strongly agree) } \\
\text { B: The prerequisites for receiving material needed to produce products stated in the } \\
\text { production plan in the right quantities are good. (1: Strongly disagree, 7: Strongly } \\
\text { agree) }\end{array}$ \\
\hline Detail complexity \\
$\begin{array}{l}\text { How many different planning objects (e.g., products, product types, product groups) } \\
\text { are included in the production plan? (1: Few <10, 7: Many >500) }\end{array}$ \\
\hline
\end{tabular}

\section{MPS maturity}

\begin{tabular}{|l|l|}
\hline $\begin{array}{l}\text { Measure } \\
\text { Cronbach's } \boldsymbol{\alpha})\end{array}$ & Survey item \\
\hline MPS maturity & $\begin{array}{l}\text { Average of the following items: } \\
\text { A: The MPS process is implemented in consecutive, repetitive steps consisting of } \\
\text { activities and meetings with clearly stated goals. (1: Strongly disagree, 7: Strongly } \\
\text { agree) } \\
\text { B: Several key persons from different departments participate in the MPS process. (1: } \\
\text { Strongly disagree, 7: Strongly agree) } \\
\text { C: The cooperation of sales, marketing, and production organisations is active and } \\
\text { effective. (1: Strongly disagree, 7: Strongly agree) }\end{array}$ \\
\hline
\end{tabular}

\section{MPS Performance}

\begin{tabular}{|l|l|}
\hline Measure & Survey item \\
\hline $\begin{array}{l}\text { Inventory } \\
\text { turnover rate }\end{array}$ & $\begin{array}{l}\text { How does the plant's average inventory turnover compare to that of your major } \\
\text { competitors? (1: Much lower, 7: Much higher) }\end{array}$ \\
\hline Delivery service & $\begin{array}{l}\text { How does the plant's delivery service to customers (i.e., delivering the right product } \\
\text { in the right quantity at the right time) compare to that of your major competitors? (1: } \\
\text { Much worse, 7: Much better) }\end{array}$ \\
\hline Plan feasibility & $\begin{array}{l}\text { Average of the following items: } \\
\text { A: To what extent is it possible to produce according to the master production } \\
\text { schedule? (1: Small, 7: Large). } \\
\text { B: To what extent is the plan used as a frame of operational planning (1: Small, 7: } \\
\text { Large). }\end{array}$ \\
\hline
\end{tabular}

